\title{
ESTÁGIO EM FORMAÇÃO DE FORMADORES NO DESENVOLVIMENTO CURRICULAR DO CURSO DE PEDAGOGIA DA UFMA
}

Sirlene Mota Pinheiro da Silva

Resumo

Este artigo discute experiências desenvolvidas no Estágio em Formação de Formadores do Curso de Pedagogia da Universidade Federal do Maranhão (UFMA). Problematiza o estágio e sua articulação entre pesquisa, extensão e formação continuada, momento em que discentes e docentes constituem-se em aprendizes, a partir das experiências e desafios vivenciados nos cursos de extensão desenvolvidos. Percebeuse a importância da pesquisa ao longo da formação inicial e que o estágio se configura como um importante dispositivo na formação profissional, pois traz consigo a possibilidade de articulação entre o que é estudado na academia e o exercício profissional.

Palavras-chave: estágio em formação de formadores; currículo; formação continuada.

\section{STAGE IN TRAINING OF TRAINERS IN THE CURRICULAR DEVELOPMENT OF UFMA'S PEDAGOGY COURSE}

\begin{abstract}
This current article is supposed to discuss experiences which were developed in the Internship in Formation of Trainers from the Pedagogy Course of the Federal University of Maranhão (UFMA). It talks through the internship and its articulation among research, extension and continuing training, when students and teachers are apprentices, based on the experiences and challenges experienced in the extension courses developed. It was perceived the importance of research throughout the initial training and that the internship is an important device in professional training, because it brings with itself the possibility of articulation among what is studied in both academy and professional practice.
\end{abstract}

Keywords: internship in formation of trainers; curriculum; continuing training.

\section{PASANTÍA EN FORMACIÓN DE FORMADORES EN EL DESARROLLO CURRICULAR DEL CURSO DE PEDAGOGÍA EN}

Resumen

Este artículo analiza las experiencias desarrolladas en el Curso de Formación de Formadores del Curso de Pedagogía de la Universidad Federal de Maranhão (UFMA). Cuestiona la pasantía y su articulación entre investigación, extensión y educación continua, un momento en el que estudiantes y docentes se convierten en aprendices, a partir de las experiencias y desafíos vividos en los cursos de extensión desarrollados. Se notó la importancia de la investigación a lo largo de la formación inicial y que la pasantía se configura como un dispositivo importante en la formación profesional, porque trae consigo la posibilidad de articulación entre lo que se estudia en la academia y la práctica profesional.

Palabras clave: pasantía en formación de formadores; plan de estudios; educación continua. 
DOI: $10.12957 /$ teias. $\%$ Y.45654

\section{INICIANDO UMA CONVERSA}

O estágio no Curso de Pedagogia da Universidade Federal do Maranhão (UFMA) se configura como um importante componente curricular na formação profissional, pois traz consigo a possibilidade de articulação entre o que é estudado na universidade e o exercício da profissão, possibilitando a/ao estudante/estagiário/a o desenvolvimento de uma visão crítica, por meio da aproximação com a realidade que deverá enfrentar como professor/a na sua vida profissional, constituindo-se ainda como um campo de formação e de construção da identidade docente. No entanto, muitos são os questionamentos quando se trata da relação entre o estágio, a pesquisa e a formação continuada de professores/as que atuam na rede pública e comunitária de ensino, dos quais se destacam: em relação à formação docente, por meio de experiências vivenciadas no espaço escolar, bem como diante dos desafios enfrentados, qual a contribuição do estágio? É possível o/a estudante em formação atuar como formador em cursos de formação continuada de professores em exercício?

Esses questionamentos têm sido constantes nos debates e discussões acerca do estágio supervisionado e mais especificamente no Estágio em Formação de Formadores do Curso de Pedagogia da UFMA. Sendo assim, neste estudo, discutimos aspectos do Estágio em Formação de Formadores oferecido pelo Curso de Pedagogia da UFMA, destacando-se algumas das ações desenvolvidas pelas/os discentes estagiárias/os, junto a docentes da rede pública e comunitária de São Luís - MA. Este estágio se configura como uma oportunidade de pesquisa e de construção de novos conhecimentos a respeito das práxis educativa, na qual docentes e discentes constituem-se aprendizes a partir das experiências e desafios vivenciados, pois, conforme citado por D'Ávila (2013), há a necessidade de investigarmos sobre as relações entre currículo e profissionalização docente.

Ao refletirmos sobre o estágio curricular supervisionado na formação do/a pedagogo/a, faz-se necessário discutir sobre o currículo formal, ou seja, os documentos legais que norteiam a organização curricular dos cursos de Pedagogia. Esse recorte pode ser delineado a partir dos saberes docentes e da relação teoria prática evidenciados no estágio curricular supervisionado. Assim, neste texto será abordado, principalmente, a formação do/a pedagogo/a para a função de formador/a de professores/as da educação básica.

Compreendemos que o estágio vai além da prática e traz aprendizagens enriquecedoras que aproximam o/a formando/a com a realidade educacional que surge da reflexão baseada no contexto real de atuação e vivência escolar, possibilitando o debate entre o que é estudado na universidade e o vivido no espaço de formação. Dentre os componentes formativos, o estágio torna-se um momento especial por desenvolver-se em condições particulares que envolvem as dimensões intelectuais, emocionais e atitudinais dos sujeitos com atividades que envolvem um trabalho coordenado com outras pessoas em outro ambiente externo à sala de aula. Conforme aponta Zabalza (2014), torna-se também uma experiência pessoal. Sobre esta experiência, o autor refere-se à diferença entre o "ser" e o "estar" na profissão docente. Para o autor, o estágio seria o momento em que estas duas características do ser estudante da profissão docente se fazem presentes, pois exige um envolvimento pleno dos/as estagiários/as e requer um novo posicionamento diante de uma nova situação, "[...] de pessoas e tarefas também novas; não se trata de pôr em jogo apenas os recursos intelectuais, não se trata de ler ou memorizar algo, mas sim de que toda a sua pessoa entre em jogo" (ZABALZA, 2014, p. 236).

Por essa razão, o estágio deve ser analisado como uma experiência pessoal, uma vez que as características pessoais influenciam substancialmente as vivências desta atividade, que se diferencia 
DOI: $10.12957 /$ teias. $\%$ Y.45654

das demais atividades acadêmicas pelo fato de envolver situações reais que requerem atitudes diferentes das utilizadas nas aulas na academia. Tão importantes quanto a instrução na sala de aula são os estágios nos locais onde se desenvolvem atividades relacionadas às profissões que as/os estudantes almejam, como empresas, escolas, hospitais, comunidades, dentre outras. São esses espaços de conhecimento e de aprendizagem, constituídos por situações reais, que possibilitam a interação teoria e prática - a práxis. $O$ curso de formação docente contínua é uma dessas oportunidades. Ainda que de forma iniciante, o/a discente estagiário/a tem oportunidade de antecipar uma prática profissional na condição de docente; no caso deste estágio, o discente estagiário/a tornar-se também formador/a de formadores/as, sob a orientação próxima de um/a professor/a responsável.

Ao levar em consideração as experiências no Estágio em Formação de Formadores, destacamos aqui alguns dos fundamentos teóricos, curriculares e metodológicos deste estágio, bem como apresentamos ações desenvolvidas nos cursos de formação docente continuada oferecidos por 15 estagiárias/os de turmas do oitavo e nonos períodos do Curso de Pedagogia da UFMA a professoras e professores de escolas públicas e comunitárias do município de São Luís - MA, que se dispuseram a frequentar o curso em salas de aula do Centro de Ciências Sociais - CCSo/UFMA, sob minha orientação, como supervisora deste estágio. Para o desenvolvimento dos minicursos e oficinas, foram divididas duplas ou trios, conforme veremos a seguir.

\section{FUNDAMENTOS TEÓRICOS, CURRICULARES E METODOLÓGICOS DO ESTÁGIO EM FORMAÇÃO DE FORMADORES DA UFMA}

O estágio supervisionado é um tema relevante nos debates sobre formação profissional e tem importância quando se trata de formação de professores e professoras, do exercício da docência e da construção da identidade docente. Pimenta (2001) aponta que o estágio, por excelência, é o momento de reflexão sobre a construção e o fortalecimento da identidade, e que, ao vivenciá-lo, alunos/as e professores/as compreendem que se podem tecer os fundamentos e as bases indenitárias da profissão docente.

No entanto, entendemos que não é simples pôr em prática e de forma articulada os componentes curriculares em cursos de licenciaturas. Conforme aponta D'Ávila (2013):

A falta então de um currículo interdisciplinar que configure uma formação em rede tem ocasionado o fracionamento do conhecimento profissional propiciado ao estudante de licenciatura. De modo que o mesmo conclui curso sem uma visão integrada de docência e pesquisa, por exemplo, ou entre o que estudou no currículo do seu curso e o que precisa praticar como professor da educação básica. O cenário continua problemático, pois, as licenciaturas em seus diferentes cursos parecem afigurar-se como ilhas localizadas num grande arquipélago (p. 25)

Tendo em vista a realidade apontada pela autora, sendo um problema percebido nas matrizes curriculares dos cursos de formação de professores/as, é possível constatar que, em algumas realidades, o currículo formal diverge do real no processo de formação. Contudo, o Curso de Pedagogia da UFMA, especialmente no Estágio de Formação de Formadores, oferecido a discentes do oitavo período do turno vespertino e nono período do curso noturno, tem buscado superar esses desafios, desenvolvendo ações que articulem ensino, pesquisa e extensão, com oferta de cursos de formação continuada sobre as mais diferentes temáticas e de forma interdisciplinar. 
DOI: $10.12957 /$ teias. $\%$ Y.45654

Lipovetsky, Lisita e Rosa (2001), sinalizam que, atualmente, existem quatro perspectivas ou tradições de formação docente. Sendo elas: a perspectiva acadêmica, com foco na formação de um especialista em uma ou várias áreas de conhecimento, tendo como principal objetivo o domínio do conteúdo a ser ensinado; a perspectiva de racionalidade técnica, com ênfase na formação de um técnico que tenha condições de agir conforme regras ou técnicas derivadas do conhecimento científico; a perspectiva prática, que forma o professor/a para a prática, sem criticidade ou reflexão; e a perspectiva que fundamenta o Estágio em Formação de Formadores da UFMA, que propõe uma formação de professores/as para o ensino como atividade reflexiva e critica, com compromisso político e social.

Assim, cada estudante vivencia de uma maneira única, que depende da organização do estágio e de como este se dispõe a enfrentar essa experiência: o que será aprendido nos conteúdos, se referem às metas ou resultados que devem ser alcançados; o desenvolvimento pessoal se refere a forma como cada estudante constrói significados por meio de suas experiências; refere-se à metaaprendizagem, ao estilo pessoal de aprendizagem (SILVA, 2019, p. 131).

Os/as estudantes chegam a este momento cheios de expectativas, alguns com energia e vontade de envolver-se e intervir, outros incomodados pela mudança de contexto. Essa diferença de atitudes influi de forma significativa nas dinâmicas de aprendizagem durante o estágio. $\mathrm{Na}$ aprendizagem experiencial os fatores pessoais tornam-se relevantes no êxito da aprendizagem, exigindo diversas capacidades do/a estudante. Dentre elas, Zabalza (2014) destaca: capacidade para envolver-se em experiências concretas; atitude de observação reflexiva; capacidade de conceituação abstrata; capacidade de experimentação ativa.

No que se refere ao contato com a realidade, quando analisamos as concepções de sociedade, de escola e o próprio currículo das instituições, perpassando pela questão do ensino e da formação docente, temos diversas perspectivas de formação de professores e de como estas formações devem articular conhecimentos teóricos e práticos. Essa articulação de conhecimentos nos auxilia a compreender como se operacionaliza a formação continuada de professores/as nas escolas e como podemos desenvolvê-la com base no diagnóstico das necessidades formativas, articulando com os conhecimentos das três unidades que fazem parte do rol de conteúdo do estágio: o estágio como formação e produção de saberes, a escola como lócus de formação docente e, por último, a organização, o desenvolvimento e a avaliação de projetos de formação (LISITA, ROSA, LIPOVETSKY, 2001).

Segundo o Regulamento de Estágio dos Cursos de Graduação, Resolução n. 1.191 CONSEPE-UFMA, de 03 de outubro de 2014, o objetivo do estágio é possibilitar ao estudante a ampliação de conhecimentos teóricos e práticos em situações reais de trabalho, além de proporcionar o desenvolvimento de competências e habilidades práticas e os aperfeiçoamentos técnicos, científicos e culturais, através de contextualização dos conteúdos curriculares e do desenvolvimento de atividades relacionadas, de modo específico com sua área de formação.

Em relação ao Projeto Pedagógico do Curso de Pedagogia da UFMA (2009), cumpre ressaltar que foi organizado tomando por base alguns princípios norteadores propostos e as disciplinas que constituem o currículo se organizam em torno de quatro eixos formativos, cada um deles devendo garantir a construção de um determinado grupo de conhecimentos teórico-práticos necessários ao exercício profissional. O eixo formativo 1, "Fundamentos sócio-históricos e político-culturais da educação", permite a compreensão e explicação do fenômeno educativo. O eixo formativo 2, "Políticas e gestão de sistemas educacionais, escola e organização do trabalho 
DOI: $10.12957 /$ teias. $\%$ Y.45654

pedagógico", visa garantir o domínio dos conhecimentos teórico-metodológicos que permitirão desenvolver as diferentes dimensões do trabalho pedagógico nos sistemas educacionais e na escola, numa perspectiva de integração, ampliando a compreensão das relações sociais que se desenvolvem nestes espaços. Este eixo é subdividido em três subeixos: gestão de sistemas educacionais, formação para a docência e práticas educativas integradoras. E o eixo formativo 3, "Estudos diversificados e de aprofundamento em áreas específicas", objetiva propiciar o atendimento ao princípio da flexibilidade, comportando escolhas por parte dos alunos de acordo com interesses e necessidades individuais.

No Projeto Pedagógico do Curso de Pedagogia da UFMA (2009, p. 66), o Estágio em Formação de Formadores integra o eixo formativo 2 e o terceiro subeixo, com a seguinte ementa:

A Formação Continuada de professores: modelos, concepções, tendências e políticas atuais. A prática pedagógica, a organização, desenvolvimento e avaliação de Projetos de Formação Continuada para profissionais da Educação a partir do levantamento de necessidades da escola, do Sistema Educacional e das indicações do Projeto Político Pedagógico da unidade escolar. (UNIVERSIDADE FEDERAL DO MARANHÃO, 2009, p. 66)

Logo, durante todo o percurso de sua vida acadêmica juntamente com os estágios, os/as futuros/as educadores/as poderão observar e ser coparticipantes do processo, sendo necessária a atitude de pesquisador/a para solucionar/atenuar desafios e dificuldades dentro da realidade em que estão inseridos, como nas intervenções dos estágios curriculares.

\section{FORMAÇÃO DOCENTE E CONTINUADA PERMEADA PELA PESQUISA E EXTENSÃO}

Com críticas endereçadas às diferentes perspectivas de formação de professores discutidas nos encontros teóricos, em especial à concepção que associa formação a treinamento, defendemos os pressupostos contidos na proposta feita por Lisita, Rosa e Lipovetsky (2013, p. 109), que acreditam em uma formação docente que contemple e dê a possibilidade ao/a professor/a de "[...] teorizar a sua prática, participar da produção de seu próprio conhecimento profissional, propor mudanças e agir de forma autônoma, tanto no contexto de sua atuação quanto no contexto social mais amplo". Para as autoras, a formação inicial perpassada pela prática de pesquisa oferece muito mais subsídios para que o/a futuro/a educador/a lide com as mais diversas situações e problemas em relação ao ensino e a aprendizagem dos alunos e alunas. Um/a profissional formado com base sólida em pesquisa estará mais preparado para lidar com "[...] a natureza complexa e incerta do trabalho docente" (p. 109).

Voltamos, então, nosso olhar para a formação docente, com alguns questionamentos: será que nossos alunos e alunas estão sendo formados/as para ter autonomia no campo de atuação profissional? Estão aprendendo a refletir sobre a prática, investigar o fazer pedagógico e produzir conhecimentos? Ao refletir essas questões, percebemos a importância da pesquisa ao longo da formação inicial, para que se tornem profissionais mais autônomos em relação ao objeto de trabalho.

Entendemos que uma formação fundamentada na pesquisa e na extensão prepara os/as profissionais para agir nas diversas situações que possam surgir no espaço educativo, tendo mais autonomia para investigar sua prática, refletir sobre ela e procurar soluções coerentes ao problema. $\mathrm{O} / \mathrm{A}$ professor/a se torna produtor/a de conhecimentos acerca de seu próprio objeto de trabalho 
- o ensino, levando-se em consideração que a perspectiva adotada no desenvolvimento do Estágio em Formação de Formadores e que a preocupação está voltada também para que os/as discentes de Pedagogia atuem como formadores/as, percebam e considerem a complexidade do trabalho docente, estimulando os profissionais da educação a internalizarem a pesquisa como um caminho para a realização do seu trabalho no ambiente escolar, incentivando a formação de professores pesquisadores.

Desta forma, o Estágio em Formação de Formadores consolida-se como uma atividade de ensino que promove o estreitamento de parcerias entre escolas de educação básica e a UFMA, promovendo momentos de construção e desconstrução de conceitos, através da reflexão/troca de experiências entre estagiários/as e professores/as. O que, nas palavras de Lima (2001, p. 28) "[...] não é um treinamento comum, verticalizado, burocratizado, mas um curso com características próprias, em consonância com a realidade na qual estamos inseridos, com as reais possibilidades dos estagiários e as aspirações da comunidade". Concordamos com a autora, uma vez que formação não é treinamento, e dessa forma não buscamos a solução de problemas gerais ou padronizados.

Cada escola representa uma realidade, cada professor/a enfrenta situações problemáticas e são estas situações que representam a alavanca da "[...] inovação institucional como objetivo prioritário da formação continuada" (IMBERNÓN, 2010, p. 57). Assim, entendemos que a formação continuada deve corresponder às necessidades formativas enfrentadas pelo/a professor/a na escola em que atua, tornando-se significativa para este/a profissional, uma vez que os temas sugeridos não são escolhidos de forma aleatória ou de modo vertical como geralmente ocorre.

É importante ressaltar que formação inicial e continuada é indispensável aos/as docentes, cabendo a estes/as, sobretudo, refletir sobre a sua aprendizagem e prática, assimilando-as, problematizando-as à realidade em que se encontra, assegurando assim condições de ensino e de aprendizagem mais eficientes e proporcionando o desenvolvimento das competências profissionais.

Neste processo, no curso de Pedagogia da UFMA, o Estágio em Formação de Formadores, oferecido para discentes do oitavo período do turno vespertino e nono período do turno noturno, objetiva vivenciar experiências formadoras que possibilitem a construção de conhecimento sobre o processo de formação continuada de professores da educação básica e promovam a apropriação de saberes e habilidades sobre o fazer pedagógico por meio da organização de diagnósticos de necessidades formativas, elaboração e desenvolvimento de projetos de formação continuada.

Os projetos de extensão/formação continuada são organizados em cinco fases: diagnóstico das necessidades formativas nas escolas; fundamentação teórica dos temas sugeridos; planejamento e organização das atividades e recursos; operacionalização da proposta; e avaliação. Ao realizar o diagnóstico, fundamentação teórica e planejamento das ações, podemos afirmar que, no desenvolvimento deste estágio, as atividades são valorizadas "[...] para o desenvolvimento da capacidade de reflexão e da realização de pesquisas, tomando a prática existente de outros profissionais e dos próprios professores nos contextos institucionais (PIMENTA, LIMA, 2006, p. 14). Dessa forma, tentamos operacionalizar a ideia de "professor reflexivo e pesquisador", sendo este o grande desafio das propostas curriculares dos cursos de licenciatura e dos planos de ensino de professores/as formadores/as.

A formação de formadores é desenvolvida por meio de minicursos e oficinas, planejados e desenvolvidos de acordo com as temáticas sugeridas na fase do diagnóstico. Os cursos de formação acontecem em salas de aula no campus da UFMA e são ministrados/as pelos/as estagiários/as em processo de formação inicial, sob a supervisão e orientação de um/a professor/a do Departamento 
de Educação I. Lima (2001), considera o minicurso como um aprofundamento, discussão e troca de experiências sobre os temas sugeridos pelo público.

Os temas das formações e dos minicursos/oficinas foram pensados após os diagnósticos realizados com cerca de 70 professoras/es da educação infantil e ensino fundamental de escolas públicas municipais e comunitárias de São Luís - MA, momento em que os/as estagiários/as aplicaram um questionário organizado em sala, durante a etapa inicial do estágio. Nesta etapa, são estudados e discutidos textos que tratam sobre estágios e formação continuada, além das orientações sobre as fases seguintes. Após a organização do questionário de diagnóstico, as/os discentes foram divididos em grupos para visitarem escolas circunvizinhas, aplicar o questionário aos/as professores/as e convidá-las/os a participar do curso de formação.

Após os diagnósticos, iniciam-se os estudos para fundamentação teórica e metodológica, seguidos da organização de projetos de extensão, conforme temáticas sugeridas por professoras/es em suas respostas ao questionário. Cada uma das temáticas foi planejada e desenvolvida por dois ou três estagiárias/os, com dez horas de duração, trabalhados em dois dias, sendo duas temáticas voltadas à educação infantil e quatro para o ensino fundamental, totalizando 60 horas de atividades, oferecidas para 58 professoras e professores que aceitaram participar do curso de formação continuada - 22 docentes da educação infantil e 36 docentes do ensino fundamental -, conforme explicitado a seguir.

\section{Projetos de extensão para a educação infantil}

Para pensarmos o desenvolvimento das oficinas oferecidas pelas estagiárias do período às professoras da educação infantil participantes da formação, é fundamental retomarmos a definição trazida pelas Diretrizes Curriculares Nacionais para a Educação Infantil (Resolução CNE/CBE n. 5, de 17 de dezembro de 2009). Essas diretrizes instituem que:

Art. $3^{\circ} \mathrm{O}$ currículo da Educação Infantil é concebido como um conjunto de práticas que buscam articular as experiências e os saberes das crianças com os conhecimentos que fazem parte do patrimônio cultural, artístico, ambiental, científico e tecnológico, de modo a promover o desenvolvimento integral de crianças de 0 a 5 anos de idade (BRASIL, 2009, p. 01).

Nas diretrizes, são destacadas que as práticas pedagógicas em creches e pré-escolas devem ser norteadas por atividades que envolvam constantes interações e brincadeiras entre as crianças. Com este entendimento, dentre os minicursos e oficinas desenvolvidos nos cursos de formação para a educação infantil, podendo ser adequadas para o ensino fundamental, tivemos:

\section{Recreação e Musicalização: caminhos para a formação integral da criança na educação infantil}

Pensando em produzir conhecimentos sobre o pensar e o fazer docentes, a oficina foi organizada e desenvolvida por duas estagiárias. A proposta inicial foi discutida em sala de aula com as/os demais discentes e a docente supervisora, momento em que foram sugeridas algumas inclusões e adequações para o desenvolvimento das atividades.

$\mathrm{Na}$ operacionalização da oficina objetivou-se que as professoras participantes pudessem compreender a importância da recreação e musicalização para a formação integral da criança na educação infantil, uma vez que promove a interação entre seus pares, além de revelar o modo como as crianças se relacionam e exploram o mundo. 
DOI: $10.12957 /$ teias. $\%$ Y.45654

Cumpre ressaltar que, atreladas à formação integral da criança na educação infantil, a recreação escolar pode ser compreendida como as "[...] atividades e brincadeiras desenvolvidas dentro de um ambiente escolar, mediadas por professores/as ou recreacionistas, tendo como objetivo a expressão humana com prazer e alegria e o desenvolvimento de habilidades motoras e afetivas" (HAETINGER, HAETINGER, 2012, p. 17).

Dentre os resultados alcançados, destacamos que as estagiárias formadoras, embora tivessem demonstrado, a princípio, algumas dificuldades na comunicação com as professoras participantes, no decorrer das atividades conseguiram concluir o que haviam planejado, possibilitando ricas trocas de experiências e o conhecimento de realidades diversas, exemplificadas durantes as discussões das atividades propostas.

\section{Ensinando e Aprendendo Matemática através dos jogos}

A matemática não se restringe apenas à escola, ela surge de forma espontânea e natural na sociedade que a criança está inserida, a partir de experiências que esta oferece. Essas experiências, desafios e dificuldades que vão surgindo fazem com que a criança, ao tentar solucioná-las, aprofunde pouco a pouco o conhecimento das diversas noções matemáticas. Será na educação infantil que a criança iniciará com o desenvolvimento do seu raciocínio lógico, quer seja pela flexibilidade de atividades, quer pela riqueza de criatividade dos exercícios. Ajudar a pensar matematicamente acerca de um fato ou um problema faz com que haja relação com a capacidade de juntar, separar, retirar, estabelecer correspondência entre objetos, descobrindo suas propriedades (cor, tamanho, forma...).

Ao se utilizar dessas atividades espontâneas e estabelecendo relações, a criança constrói noções matemáticas, desenvolvendo as habilidades motoras e de percepção necessárias, e isto deverá ser o ponto de partida para o trabalho com a Matemática na educação infantil. Por isso, a oficina objetivou que professores/as participantes pudessem utilizar jogos e brinquedos com materiais recicláveis e a dinâmica problemoteca como recurso no processo ensino-aprendizagem. A problemoteca trata-se de uma caixa decorada com diferentes símbolos e imagens. Neste caso, foram utilizadas cores primárias, formas geométricas e alguns números, e depositadas fichas com situações problemas.

Após a explanação teórica, utilizando-se slides com conceituações e imagens sobre o assunto, as duas estagiárias responsáveis pela oficina passaram a caixa entre as professoras participantes para que elas retirassem uma ficha e respondessem o problema proposto. No momento, foi explicado que as situações problemas devem ser adequadas à faixa etária e nível de escolarização da criança. Vale ressaltar que os processos de resolução dos problemas são variados e que cabe ao professor/a analisar as respostas e discuti-las com os/as discentes, buscando sempre uma sistematização de ideias e conceitos, devendo ainda ser observado o nível de leitura e compreensão lógica de cada criança.

Dentre os resultados alcançados, apesar do receio inicial, a formação teve efeitos positivos, contando com a participação ativa de todas as professoras presentes, além de terem sugerido que a dinâmica da problemoteca poderia ainda ser utilizada na abordagem de assuntos diversos e não apenas na matemática. O grupo de professoras participantes também incentivou a continuidade das formações do Estágio em Formação de Formadores, afirmando a possibilidade de a universidade cumprir seu papel social, relacionando-se com a comunidade por meio dos projetos de extensão desenvolvidos.

Projetos de extensão para o ensino fundamental 
DOI: $10.12957 /$ teias. $\%$ Y.45654

No momento do diagnóstico com professoras/es do ensino fundamental, uma das temáticas mais solicitadas foi sobre educação inclusiva, seguido dos seguintes temas: indisciplina, tecnologias educacionais, relações de gênero e sexualidade. Cumpre ressaltar ser um grande desafio estabelecer diálogo entre o currículo real e a efetivação de um ensino que vise à inclusão escolar, o uso das novas tecnologias e o combate à discriminação de gênero e da sexualidade. Assim, no processo de revisão de literatura para o planejamento de minicursos sobre as temáticas, organizamos as estagiárias e estagiários formadoras/es em duplas e um trio, para que buscassem tanto os fundamentos teóricos e legais, quanto alguns recursos tecnológicos e metodologias diversificadas para desenvolverem os minicursos e oficinas a seguir:

\section{Educação inclusiva: aspectos legais e recursos tecnológicos facilitadores na relação ensino- aprendiragem}

A oficina sobre educação inclusiva foi um dos temas mais solicitados pelas professoras e professores das escolas visitadas. Ressaltamos ainda que este é um assunto que possui repercussão de um movimento mundial, buscando-se a garantia de que todos os alunos e alunas possam frequentar a escola regular, valorizando-se a diversidade e devido à Constituição Federal de 1988 e o Plano de Desenvolvimento da Educação (PDE) aprovado em 2007. Segundo as estagiárias e o estagiário que desenvolveram esta oficina, as metodologias e recursos desenvolvidos pensados para a tarefa serviriam como instrumentos potencializadores do processo ensino aprendizagem, por entenderem que as novas tecnologias têm um importante papel como recurso na educação inclusiva.

No primeiro dia da formação, foram apresentados conteúdos teóricos e algumas leis e políticas educacionais voltadas à educação inclusiva. $\mathrm{O}$ objetivo foi abordar a ideia de que a inclusão é mais do que a garantia de acesso de alunos e alunas com deficiências nas instituições de ensino, mas sim a garantia e eliminação de obstáculos que limitam a aprendizagem e participação discente no processo educativo. No dia seguinte, foram realizadas dinâmicas e jogos de integração, apresentação de slides com sugestões de recursos tecnológicos que possam facilitar o processo ensino aprendizagem na educação inclusiva, bem como apresentação de vídeos, sempre seguidos de diálogos com as/os participantes, com exemplificações de suas realidades nas escolas. $\mathrm{O}$ trabalho foi concluído com êxito pelas estagiárias, obtendo profícuos diálogos e interação entre as/os participantes.

\section{A tecnologia como aliada do processo de ensino-aprendizagem}

As escolas buscam cotidianamente atividades que promovam a melhoria do processo ensino-aprendizagem, mas apesar dessa busca comum nas instituições escolares, muitas ainda não conseguiram incluir a tecnologia dia a dia da escola. Muitas vezes o uso da tecnologia é considerado algo que atrapalha o desenvolvimento, visto que em muitos casos seu uso é realizado de forma incorreta. Neste contexto, as estagiárias questionavam: como a prática docente associada às tecnologias pode contribuir no desenvolvimento das crianças dos anos iniciais do ensino fundamental? E para que os/as professores/as participantes pudessem reconhecer o uso das tecnologias na sala de aula como ferramenta facilitadora no processo ensino-aprendizagem, no primeiro dia, foram apresentados alguns recursos tecnológicos como web quest, podcast e celular por meio de aula expositiva dialogada, com exposição de slides, para que pudessem perceber algumas das possibilidades no desenvolvimento de atividades de escrita com seus alunos e alunas a partir de atividades coletivas realizadas durante a oficina. 
Para tratar da informática na educação, e, sobretudo, para contemplar os objetivos práticos definidos pela equipe formadora, no segundo dia foi utilizado o laboratório de informática localizado no Prédio Paulo Freire da UFMA. Este momento foi iniciado com a exposição do vídeo "As novas tecnologias em sala de aula", da TV Escola, seguido de breves comentários. Em seguida, a turma foi dividida em grupos para utilização dos aparelhos disponíveis na sala, quando as estagiárias apresentaram o computador e seus componentes, bem como a instalação do aparelho data show. Em seguida, cada grupo organizou um Power point com conteúdo que trabalhariam com seus alunos e alunas e que seriam apresentados no último dia da formação, após a conclusão dos minicursos e oficinas.

Como resultados, destacamos que tanto as estagiárias, quanto as/os professoras/es participantes demonstraram grande envolvimento com a temática, compreendendo algumas das funcionalidades das multimídias em sala de aula, bem como a internet como instrumento de aprendizagem.

\section{Indisciplina: o que não nos contaram acerca da prática docente?}

Considerando que a escola, ao longo do tempo, teve o papel de disciplinar e homogeneizar as pessoas e, mesmo esta sendo uma problemática presente nas salas de aula, durante o curso de graduação esta temática não é discutida nas disciplinas que compõem a matriz curricular do curso de Pedagogia. Com isso, as estagiárias sentiram a necessidade de aprofundar o estudo sobre o assunto, muito presente no cotidiano das escolas públicas e privadas não só do Brasil, mas de diversos países, desenvolvendo uma oficina que objetivou expandir os conhecimentos a respeito da indisciplina em sala de aula, buscando-se alternativas e possíveis formas de superação.

No primeiro dia do minicurso, as estagiárias iniciaram com uma dinâmica "quebra-gelo", momento em que foram espalhadas figuras pela sala e, ao som de uma música, cada participante deveria escolher uma com que se identificasse. Posteriormente, deviam apresentar a figura aos demais, explicando os motivos da escolha, relacionando-a à sua personalidade. Essa dinâmica gerou um debate interessante sobre a realidade de cada um deles/es, bem como sobre a forma como lidam com diversos comportamentos. Depois, foram trabalhados alguns conceitos por meio de aula expositiva, seguida de apresentação de um trecho do filme "Cidade dos homens", que aborda a questão da indisciplina e a necessidade do/a professor/a buscar estratégias para que as aulas funcionem. No segundo dia, iniciaram com uma dinâmica de empatia, demonstrando a importância de se colocarem no lugar do outro, dando atenção quando o outro fala. A dinâmica possibilitou o diálogo sobre a relação entre respeito e indisciplina na sala de aula, bem como a problematização sobre o tema. As/os participantes avaliaram positivamente e fizeram muitos elogios sobre as dinâmicas realizadas pelas estagiárias, incentivando também a continuidade das formações oferecidas pelo Estágio em Formação de Formadores do curso de Pedagogia da UFMA.

\section{Educação sexual: gênero, diversidade e orientação}

Falar em educação sexual com professores/as do ensino fundamental justifica-se, pois seus alunos e alunas vivem em constante interação com pessoas adultas e colegas, aprendem comportamentos e normas de conduta que os/as acompanham em suas relações sociais. Para que esses comportamentos sejam adequados à idade de cada criança é necessária uma discussão de forma clara e sem barreiras, visto ser este um tema ainda pouco debatido na escola, por certas polêmicas em torno do assunto, mitos e preconceitos, dentre outros fatores que incidem diretamente na área educacional. Logo, o minicurso desenvolvido pelas estagiárias objetivou 
aprofundar o entendimento sobre as questões de gênero, diversidade e orientação sexual na sociedade em geral e na escola em particular, a fim de promover uma educação democrática e inclusiva, sem tabus e discriminações.

No campo do currículo educacional, cumpre ressaltar que, no final do século XX e início do século XXI, ganham destaque algumas problemáticas que acompanham as transformações nas sociedades tanto em países desenvolvidos quanto em países emergentes, das quais se destacam questões da diversidade, como a de gênero e da sexualidade. Tais categorias passam a ser vistas como fundamentais para se compreender como o currículo contribui para a consolidação de certas relações de poder que ultrapassam a simples dimensão econômica (de classe). Silva (2005) apresenta as perspectivas críticas sobre relações de gênero e pedagogia feminista dizendo que esta passou a questionar o fato de não levarem em consideração a questão de gênero, classe e raça no processo de produção e reprodução das desigualdades.

No contexto até aqui descrito, destacamos ainda o entendimento de Almeida e Pimenta (2014, p. 29) sobre estágio, quando ressalta que o percebe como um campo de conhecimento que "[...] envolve estudos, análise, problematização, reflexão e proposição de soluções para o ensinar e o aprender, e que compreende a reflexão sobre as práticas pedagógicas, o trabalho docente e as práticas institucionais, situados em contextos sociais, históricos e culturais". Nesse sentido, o Estágio em Formação de Formadores caracteriza-se como mediação entre professores/as supervisores/as, os estudantes em curso, sendo estes os/as estagiários/as que atuam também como formadores/as de professores/as das escolas. Na realização dessas formações, esses sujeitos se colocam cuidadosos sobre as relações que se estabelecem e a partir dos quais realizam as articulações pedagógicas e percebem as possibilidades de se realizar pesquisas e intervenções, tendo os problemas da escola como fenômenos a serem analisados, compreendidos e mesmo superados.

\section{ALGUMAS (IN) CONCLUSÕES}

Realizar um estágio é sempre um desafio, especialmente quando este é desenvolvido por estudantes em processo de formação inicial, junto a professores/as que já estão no mercado de trabalho - momento em que nossas/os discentes se colocam diante de olhares experientes e críticos e, acima de tudo, por estarem tentando "ensinar" para eles/as algo novo e que pudesse facilitar o dia a dia de cada um/a. Com relação ao componente curricular Estágio em Formação de Formadores, constatamos, em síntese, que atende ao que diz o Projeto Pedagógico do Curso de Pedagogia (PPP), devendo ser considerado como um recurso integralizador dos saberes das disciplinas nas situações da prática. Isso significa que a formação docente do/a licenciado/a em Pedagogia se dá de forma articulada ao contexto de trabalho e por uma ação coletiva entre docentes formadores e discentes em processo de formação de formadores, com o intuito de articular os diferentes saberes por meio da interdisciplinaridade.

No desenvolvimento dos projetos em questão, o principal objetivo foi desenvolver formação contínua de docentes da educação infantil e ensino fundamental, buscando-se complementar e discutir saberes e fazeres do cotidiano escolar e a melhoria do processo ensino aprendizagem, destacando-se alguns desafios na contemporaneidade. Em se tratando das temáticas selecionadas para essa formação, importa referir que elas partiram do interesse dos/as professores/as da rede pública, os quais foram questionados/as sobre a necessidade de determinados conhecimentos para o enfrentamento dos problemas emergentes no cotidiano escolar. 
DOI: $10.12957 /$ teias. $\%$ Y.45654

Este estágio é conhecido por muitos alunos/as como sendo o "pior estágio", estigmatizando-o como se fosse um "bicho de sete cabeças". Dentre as dúvidas e questionamentos iniciais sobre o Estágio em Formação de Formadores e sobre determinadas questões apresentadas pelos estagiários/as, destacam-se: "Como um acadêmico de Pedagogia pode ser professor de outros professores que já têm anos de sala de aula, ou seja, que possuem muitas experiências, e nós (alunos) ainda estamos adquirindo?’. Não seria certa pretensão da nossa parte enquanto aluno/a, atuar como formador/a de profissionais já formados?”. O que podemos afirmar é que não existe pretensão e, sim, respeito mútuo entre todos que participam das formações oferecidas pelo Estágio em Formação de formadores, visto que, ao final de cada semestre letivo, ouvimos as vivências e avaliações feitas pelos/as estagiários/as formadores/as, reconhecendo este estágio como sendo muito trabalhoso, mas também muito recompensador. Confirmam o retorno dos/as professores/as que participam de todas as atividades propostas com entusiasmo, trazendo em suas falas as dificuldades que enfrentam em seus cotidianos.

Tudo isso, de certa forma, também contribui na construção e reconstrução da identidade profissional tanto nossa, enquanto professora supervisora do estágio, das professoras e professores participantes da formação, quanto de nossos/as educandos/as estagiárias/os, futuras/os pedagogas/os e professoras/es, que no exercício da formação, enquanto formadores/as, têm a possibilidade de pensar, repensar e avaliar práticas educativas desenvolvidas num estágio que apresenta a possibilidade de formação continuada, pesquisa e como dispositivo de ensino aprendizagem, atentando para novo e, acima de tudo, buscando e compartilhando conhecimentos, saberes e fazeres.

\section{REFERÊNCIAS}

ALMEIDA, Maria Isabel de; PIMENTA, Selma Garrido. Estágio supervisionado na formação docente. São Paulo: Cortez, 2014.

BRASIL. Ministério da Educação. Conselho Nacional de Educação. Câmara de Educação Básica. Resolução CNE/CEB n. 5, de 17 de dezembro de 2009. Institui as Diretrizes Curriculares Nacionais para a Educação Infantil. Diário Oficial [da] República Federativa do Brasil, Brasília, DF, 18 dez. 2009. Seção 1, p. 18.

D’ÁVILA, Cristina Maria. Docência na Educação Superior: labirintos e saídas na construção da profissionalização docente. In: D'ÁVILA, M. C.; VEIGA, I. P. A (Orgs.). Profissão Docente na Educação Superior. Curitiba - PR: CRV, 2013.

HAETINGER, Daniela; HAETINGER, Max. Jogos Recreação e Lazer. 1 ed. rev. Curitiba, PR: IESDE, 2012.

IMBERNÓN, Francisco. A formação continuada deve agir sobre as situações problemáticas dos professores. In: IMBERNÓN, Francisco. A formação continuada de professores. Porto Alegre: Artmed, 2010, p. 53-61.

LIMA, Maria Socorro Lucena. O estágio supervisionado como estratégia de integração entre a Universidade e a comunidade: uma reflexão sobre a experiência de minicurso. In: LIMA, Socorro Lucena. A hora da prática: reflexões sobre o estágio supervisionado e a ação docente. Fortaleza: Edições Demócrito Rocha, 2001, p. 24-34.

LIMA, Maria Socorro Lucena; PIMENTA, Selma Garrido. Estágio e docência: diferentes concepções. Poíesis Pedagógica, [S.1.], v. 3, n. 3 e 4, p. 5-24, out. 2006. ISSN 2178- 4442. Disponível em https://www.revistas.ufg.br/poiesis/article/view/10542. Acesso em 18 jan. 20. 
LISITA, Verbena; ROSA, Dalva; LIPOVETSKY. Formação de professores e pesquisa: uma relação possível? In: ANDRÉ, Marli (Org.). O papel da pesquisa na formação e na prática dos professores. Campinas: Papirus, 2001, p. 107-127.

PIMENTA, Selma Garrido. O estágio na formação de professores: unidade entre teoria e prática? São Paulo. 2001.

SILVA, Sirlene Mota Pinheiro da. O estágio como possibilidade de formação continuada, pesquisa e como dispositivo de ensino aprendizagem. In: SOUZA, Karla Cristina Silva (Org.) et al. O estágio supervisionado: experiências descoloniais. São Luís: EDUFMA, 2019, p. 129-145.

SILVA, Tomaz Tadeu da. Documentos de identidade: uma introdução às teorias do currículo. Belo Horizonte: Autêntica, 2005.

UNIVERSIDADE FEDERAL DO MARANHÃO. Projeto pedagógico do curso de pedagogia. Conselho Superior de Ensino, Pesquisa e Extensão - CONSEPE. São Luís, 2009. Disponível em http://www.ufma.br/portalUFMA/arquivo/Oc0sXZD9CxtFrI9.pdf. Acesso em 10 ago. 2020.

UNIVERSIDADE FEDERAL DO MARANHÃO. Regulamento de Estágio dos Cursos de Graduação da UFMA. Conselho Superior de Ensino, Pesquisa e Extensão - CONSEPE. São Luís, 2014, p. 113. Disponível em http://www.ufma.br/portalUFMA/arquivo/mHdsS5VMRSWYrcx.pdf. Acesso em 2 set. 2019.

ZABALZA. Miguel A. O estágio como experiência pessoal. In: O estágio e as práticas em contextos profissionais na formação universitária. São Paulo: Cortez, 2014, p. 235-260.

Submetido em setembro de 2020

Aprovado em outubro de 2020

\section{Informações da autora}

Sirlene Mota Pinheiro da Silva

Universidade Federal do Maranhão

E-mail: sirlene.ufma@gmail.com

ORCID: http://orcid.org/0000-0002-2481-4901

Link Lattes: http://lattes.cnpq.br/5068371548791071 